\title{
O espaço de jogo no Contexto do Drama
}

\section{The space for playing in the Drama Context}

\author{
Biange Cabral ${ }^{1}$ \\ Diego de Medeiros Pereira ${ }^{2}$
}




\section{Resumo}

Este artigo focaliza a instauração do espaço de jogo em processos de Drama, como uma forma de tensão e confronto dos participantes com as formas teatrais introduzidas pelo professor. Deste confronto, são observadas alternativas de construção da narrativa.

Palavras-chave: Drama como processo; o espaço do jogo; construção de narrativa.

\section{Abstract}

This paper draws on the playful space for games within drama processes as a way of framing students' tension and confront with the theatre forms introduced by the teacher. From this confront alternatives of developing narratives will be observed.

Keywords: Drama as process; playful space; narrative development.

ISSN: 1414.5731

E-ISSN: 2358.6958

${ }^{1}$ Profa. Dra. Universidade do Estado de Santa Catarina (UDESC), com atuação junto ao Programa de Pós-Graduação em Teatro (PPGT-CEART). bcbiange@gmail.com

${ }^{2}$ Prof. Dr. Universidade Federal de Santa Maria (UFSM). diego.pereira@ufsm.br 


\section{O Drama na perspectiva do Teatro como Pedagogia}

Drama ou Process Drama são denominações de uma prática teatral centrada na apropriação e atualização de textos, imagens, temas que pode incluir associações com objetos, ambientação cênica ou espaços diferenciados que venham a favorecer ou facilitar o desenvolvimento de um processo dramático e, eventualmente, de seu produto cênico.

Embora essa forma de fazer teatral, desenvolvida a partir dos anos 1950 por Dorothy Heathcote (1926-2011), incorpore em sua prática um texto como material de estímulo à experimentação, é por meio da criação de um espaço de jogo que a narrativa dramática se desenvolve em processo.

Diferentes perspectivas servem para construir o que conhecemos hoje como o terreno do Drama. Algumas propostas partem de ações derivadas de um pré-texto, outras de ações centradas em convenções teatrais ou ainda de ações promovidas pela atuação do professor como personagem ou ator. O que elas têm em comum é a necessidade de que os participantes joguem com os materiais postos à sua disposição.

É possível observar o desenvolvimento prioritário de cada tipo dessas ações em algumas abordagens singulares do Drama:

- Ações culturais centradas no desenvolvimento de processos dramáticos a partir de um texto como pré-texto;

- Ações culturais centradas em convenções que constroem o contexto, que desenvolvem a narrativa, que estimulem poéticas que levem ao uso seletivo da linguagem e do gesto, e que levem a ações reflexivas e

- Ações culturais promovidas pela atuação do professor personagem e/ou do professor ator.

Cecily O'Neill representa a primeira alternativa enfatizando, em sua prática, dois conceitos fundamentais - Process Drama e Pre-text. A expressão e a prática do Process Drama desenvolveram-se simultaneamente na América do Norte e na Austrália em finais de 1980, com a tentativa de distingui-la de atividades improvisacionais menos complexas e ambiciosas e situá-la em um contexto dramático e teatral associado ao patrimônio cultural desse campo de conhecimento. Não se trata do jogo pelo jogo, mas do jogo fundado na criação de um universo dramático mais complexo e envolvente para os participantes da proposta.

Segundo O'Neill (1995), 'processo' usualmente indica um evento em andamento, ao contrário de 'produto', que indica 'conclusão'. Uma peça de teatro, considerada como um produto, um objeto de arte, é uma experiência para o público; um texto dramático considerado como 'processo' visa sua apropriação e atualização pelos participantes, e pode, ou não, ser dirigido a um produto, ou seja, ser editado para apresentação pública.

O que caracteriza e distingue a abordagem de O'Neill é sua ênfase na constata-

\footnotetext{
${ }_{2}^{2}$ Programa de Pós Graduação em Artes Cênicas. Linha de pesquisa: Pedagogia do Teatro, Teatro e Educação. Orientadora: Dra. Maria Lúcia de Souza Barros Pupo. Bolsa de fomento: FAPESC. A tese está publicada com o mesmo título: VIDOR, H. B. Leitura e Teatro: aproximação e apropriação do texto literário. São Paulo: Hucitec, 2016.
} 
ção de que a experiência, em Process Drama, é mais eficaz que uma simples improvisação porque obedece às regras do evento dramático. Embora o Process Drama e os jogos de improvisação procedam sem um texto escrito a ser seguido, o primeiro inclui episódios que serão compostos ao longo da experimentação. A diferença essencial entre ambos é que o Drama não se limita a cenas ou exercícios; assim como numa peça teatral, ele se desenvolve através de episódios ou unidades cênicas.

Cada nova proposição, situação criada ou atividade realizada no processo é considerada um episódio do Drama. Podemos pensar os episódios como unidades cênicas que compõem o processo; eventos que estruturam a narrativa teatral em construção.

A organização através de episódios é comum a todas as abordagens do Drama. Implica em um relacionamento mais complexo entre as partes do trabalho do que as conexões lineares de uma sequência ou narrativa; os segmentos do trabalho são unidos como parte de uma rede de significação. A complexidade das interações, dentro de um episódio, decorre do fato de que esse se refere ao aprofundamento ou às implicações de alguma ação ou postura evidenciada no episódio anterior e, como tal, poderá incluir questões de ética e juízos de valor. Nesse sentido, o material criado em uma experimentação, alimenta as novas propostas de jogo que serão oportunizadas em um próximo episódio.

Os episódios são preponderantemente verticalizados - para questionamento, investigação e aprofundamento. A atenção para com essa verticalização dos episódios de um processo é acentuada pela autora nos exemplos que apresenta em Drama Worlds (1995). Nessa obra, O'Neill focaliza especificamente as relações entre Process Drama e teatro contemporâneo, indicando como a vanguarda teatral dos anos 1960, o trabalho experimental e teórico enfatizaram as noções de 'presença' e o 'aqui e agora', 'processo' e 'transformação', e como as influências das práticas teatrais pós-modernas repercutiram no Drama. Essa repercussão inclui fragmentação e distribuição de papéis entre o grupo, uma aproximação descontínua e não linear do enredo, a adaptação de temas e textos clássicos, a indefinição da distinção entre atores e público, uma constante mudança de perspectivas. Em decorrência, percebemos que as práticas de Drama são cada vez mais reconhecidas como experiências teatrais radicais e coerentes.

A partir dessas considerações, a autora introduz a expressão 'pré-texto' para indicar como o contexto dramático é ativado - uma palavra, um gesto, uma locação, uma história, uma ideia, um objeto, uma imagem, tanto quanto um personagem ou um texto, podem dar início ao processo. Para O'Neill,

Um pré-texto ou um enquadramento preliminar eficaz para o processo do Drama inclui claramente intenções acessíveis para os papéis que ele sugere - um testamento a ser lido, uma tarefa a ser executada, uma decisão a ser tomada, um enigma a ser resolvido, um malfeitor a ser descoberto, uma casa assombrada a ser explorada (O’Neill, 1995, p. 20).

A significância de um pré-texto está naquilo que ele implica, sobretudo para a ação. O pré-texto deve ser desconstruído ou retrabalhado de forma a ser atualizado, confrontado ou transformado pelos participantes. Sua manutenção, sem questionar 
ou imaginar as insinuações e indícios de seus componentes, levaria à explanação em vez da exploração.

Em outra perspectiva encontra-se Jonothan Neelands, cujos trabalhos estão centrados no ensino do teatro como processo de aprendizagem. Em seus livros e apresentações em conferências e congressos de Drama/Teatro ele procura afastar a dicotomia entre ambos e focalizar o Teatro como um processo ativo de investigação e o Drama como um dos procedimentos possíveis para essa investigação criativa.

Para tanto, identifica uma situação ou história como ponto de partida, como fonte do processo, e uma estratégia para introduzi-la (uma notícia de jornal, um texto teatral, documentos, imagens, entre outras possibilidades). Para Neelands (1990) a seleção dessa fonte deve ser influenciada por seu potencial de traduzir uma experiência humana de forma acurada, representar essa experiência através de uma combinação acessível de palavras, imagens e sentimentos, capturar o interesse e a imaginação dos participantes, oferecer suficientes informações para engajar emocionalmente o grupo e motivá-lo a buscar mais informações, reais ou ficcionais.

Em Structuring Drama Work - a handbook of available forms in theatre and drama (1990), Neelands afirma que a experiência teatral, assim como a de todas as demais formas artísticas, distingue-se de uma experiência na vida real, pela aplicação consciente da forma ao significado a fim de engajar o intelecto e as emoções na representação desse significado. Nesse sentido, códigos sociais e interações são representados, moldados e artisticamente definidos através das convenções dramáticas experimentadas no espaço de jogo. O pressuposto é que a compreensão das possibilidades (e limitações) das formas teatrais permite o insight dentro da mídia teatral e oferece aos estudantes o poder de exercer um maior controle sobre esse meio e seus usos pessoais e sociais.

Nessa obra, Neelands (1990) identifica exemplos pelos quais as convenções teatrais indicam a maneira através da qual 'tempo', 'espaço' e 'presença' podem ser articulados para criar diferentes tipos de significados em teatro. A identificação dessas convenções parte do princípio de que teatro não é ensinado, ao contrário, torna-se refinado e desenvolve-se pela experimentação gradual e crescente de relações complexas entre convenções e conteúdo. As convenções formam uma ponte entre a espontaneidade no teatro e a poética da arte da representação teatral.

Essas convenções estão organizadas em grupos, os quais representam quatro variedades de ação dramática:

- Ações que constroem o contexto - 'definem a situação' ou adicionam informação sobre seu contexto. Estratégias: trilha sonora, figurino, ambientação cênica, materiais inacabados, diários, cartas, jornais, etc.;

- Ações que constroem a narrativa - enfatizam a relação com a história e/ou 'o que acontecerá em seguida'. Estratégias: encontros, entrevistas, role-play, 'um dia na vida', berlinda, professor-personagem, etc.;

- Ações poéticas - criam o potencial simbólico do Drama através do uso seletivo da linguagem e do gesto. Estratégias: inversão de papéis, rituais, máscaras, cerimônias, etc. e

- Ações reflexivas - permitem rever o Drama de uma perspectiva interna ao contexto dramático. Estratégias: momento da verdade, vozes interiores, desta forma/ 
daquela forma, momentos marcados.

As estratégias que são descritas no livro desse autor incluem exemplos de seus potenciais de aprendizagem, suas conexões culturais e sua inserção em processos dramáticos distintos.

A ideia de um sistema classificatório, explica Neelands (1990), é baseada na noção de que qualquer classificação será fluída nos seus limites e servirá para responder às necessidades básicas requeridas pela participação, tanto do espectador quanto do ator na atividade dramática: necessidade de um contexto definido claramente, de criar um interesse e curiosidade sobre o argumento e um sentido de ação iminente, de reconhecer e criar uma dimensão simbólica para o trabalho, de refletir sobre os significados e temas que emergem através da experiência, de fazer escolhas sobre a forma do trabalho.

Em sua contribuição a um texto coletivo em homenagem a Dorothy Heathcote, Neelands (2012) expõe sua perspectiva ao comentar o clássico artigo de Heathcote "Signs and Portents" (Sinais e Presságios):

[...] esse artigo explica Dorothy assim como também me explica. Neste artigo ela deixa claro que o que mais lhe interessa é a alta qualidade do ensino e da aprendizagem e não uma melhor qualidade dramática. Eu estava preocupado com ambos e tomei o caminho do teatro na educação (Neelands, 2012, p. 22).

$\mathrm{Na}$ terceira perspectiva, encontra-se John O'Toole que em The Process of Drama - negotiating art and meaning (1992), questiona as suposições embutidas na palavra 'processo' e exemplificadas na diferença entre as expressões inglesas drama process (o processo de produzir um texto dramático) e process drama (drama é um processo). Esse questionamento equivale à discussão, em pauta no contexto brasileiro à época em que seu livro foi publicado, sobre o papel do teatro na escola - processo ou produto? Discussão essa ainda não superada em muitas práticas artísticas desenvolvidas nas escolas, nas quais gestores ainda cobram e esperam dos profissionais da arte e criação de um produto o mais breve possível.

O'Toole (1992, p. 02) pergunta "[...] nós sabemos o que significa 'produzir drama', mas 'prosseguir em drama' significa alguma coisa? O produto dramático é o mesmo que a produção dramática? Ambos envolvem um processo ou são coisas diferentes?". Para O'Toole, um processo em Drama pode ser definido como "negociar e renegociar os elementos da forma dramática em termos do contexto e dos objetivos dos participantes" (1992, p. 02).

Como pesquisador, editor e autor, tem-lhe sido creditada uma visão da prática do Drama como Teatro - um fazer teatral com características próprias. Nessa perspectiva ele atua e teoriza o teacher-in-role (professor-no-papel) pelo ângulo do professor-ator, expressão que cunhou em 1976 em seu primeiro livro, Theatre in Education. Enfatiza, entretanto, que o professor não deve super-atuar nem precisa ser de fato um ator.

Ackroyd (2006) destaca a habilidade de O'Toole e seu respeito e atenção com a teatralidade ao assumir papéis. A externalização dos papéis assumidos por O'Toole, segundo Ackroyd, é mais explícita do que a usual nesse campo do teatro, uma vez que lança mão de figurino, mudanças de voz, sotaques, objetos de cena e gesticulação 
ampla. Em entrevista concedida a Ackroyd (2006), O'Toole afirma considerar a ideia de 'processo' de acordo com seu real significado, espaço e tempo onde os elementos do Drama e as formas da arte dramática se cruzam e interagem com a aprendizagem.

Esses são os principais praticantes e estudiosos do Drama que contribuíram com a teorização e a consolidação desse fazer artístico dentro de diferentes sistemas de ensino. Em suas obras, enfatizam a dimensão teatral do Drama ao afirmarem a necessidade de que todo e qualquer tema ou conteúdo posto como base de um processo poderá ser experimentado somente por meio do jogo, do engajamento criativo dos participantes com a proposta. Para dar suporte a essa experimentação, diferentes recursos podem ser utilizados pelo condutor de um processo e variadas perspectivas artísticas e pedagógicas podem ser implementadas. Não há um modelo pré-definido para a instauração de um processo de Drama, ficando a critério do professor lançar mão das referências que lhe pareçam interessantes à sua proposta.

\section{Interações entre Jogo Teatral e Drama}

O Drama, ao propor uma experiência artística amparada por um contexto ficcional, instaura um espaço de jogo, e na escolha das estratégias que se valerá para sua efetiva realização, pode se associar com diferentes vertentes metodológicas utilizadas para o ensino e experimentação da linguagem teatral.

Quando associado aos Jogos Teatrais, por exemplo, o Drama representa um método de ensino centrado em distintos níveis de intervenção do professor nas formas de representar o mundo e interagir em grupos em torno de conflitos e solução de problemas cênicos, abarcados por um contexto ficcional.

Uma forma de perceber a diferença entre as duas práticas, do Jogo Teatral e do Drama, é que a primeira privilegia a representação - os alunos ao serem incitados a mostrar 'onde' estão, 'quem' são e 'o quê' estão fazendo, concentram-se na expressão física e se distanciam, muitas vezes, do contexto dramático. O papel do professor, nesse caso, é o de observar e conduzir a atuação dos alunos, tal como o condutor de uma orquestra. Diferente do processo de Drama que, ao propor formas de enquadramento distintas para uma mesma ação, espaço, texto, o professor/diretor está introduzindo novas formas de olhar a experimentação dramática em curso.

O Jogo Teatral, na perspectiva de Viola Spolin (1963) que o introduziu, está centrado no ensino do teatro como processo de aprendizagem - 'onde', 'quem', 'o quê' levam o aluno a pensar e apresentar imagens do espaço, do personagem, da ação. Se no Jogo Teatral os participantes representam papéis e os apresentam para os colegas, no Drama os participantes representam papéis, em geral coletivos, e através deles interagem com os colegas que também estão imersos na ficção.

A experimentação de papéis coletivos pelos alunos e a atuação do professor como antagonista ou parceiro, propondo desafios e intervindo no desenrolar da narrativa dramática, leva os participantes a questionarem a situação proposta a partir de seu contexto, quer ficcional ou colado ao real, permitindo que a ficção seja mantida nos dois momentos do fazer teatral - durante a produção e a recepção.

Os Jogos Teatrais podem ou não estar delimitados por um contexto dramático. O professor estabelece as regras e organiza a participação do grupo como obser- 
vador distanciado, que coordena a manifestação das opiniões e interpretações dos participantes. No caso dos Jogos estarem inseridos em um contexto ficcional, no qual a intenção seja, por exemplo, explorar possibilidades a serem incluídas em uma montagem teatral, os participantes estão liberados para explorar papéis distintos e alterá-los conforme o desenvolvimento do jogo, ou no decorrer de um novo jogo. O jogo é modificado a cada encontro, com as novas propostas de experimentação trazidas pelo professor para aquele episódio.

Um processo de Drama que se aproprie dos Jogos Teatrais pode explorar a capacidade dos participantes revelarem 'onde' estão, 'quem' são e 'o quê' pretendem. Isso a cada situação que se apresente. Nenhuma proposta metodológica necessita ser pensada isoladamente, muitas experiências artístico-pedagógicas que tem como objetivo uma montagem teatral, por exemplo, apresentam espetáculos que em seu processo de criação usaram recursos de Spolin, os associaram a Brecht, a estratégias performáticas, a recriação de textos clássicos, a materiais biográficos, entre outros.

Uma das peculiaridades do Drama diz respeito ao papel do professor que, em geral, participa ativamente do contexto dramático, seja com um papel definido ou alterando papéis no transcorrer do processo (por exemplo, diretor de uma escola onde acontecem coisas estranhas, capitão de um navio em perigo de afundar, alguém perdido que necessita da ajuda dos participantes para recuperar sua memória, entre outras possibilidades).

O professor e os estudantes assumem papéis associados ao contexto dramático e interagem em grupo a partir deles. O conceito de 'personagem' não entra em pauta como algo definido e caracterizado; os participantes assumem um papel que inclui a possibilidade de mudanças radicais frente aos argumentos, quer do professor, quer dos colegas, face a notícias ou comprovações de fora, usualmente inseridas pelo professor. Exemplificando: se o professor, no papel de coordenador de uma investigação, introduzir evidências de que o desaparecimento de alguma produção da comunidade está relacionado com pessoas ou com animais da vila mais próxima, os participantes, como moradores, por exemplo, reunir-se-ão para decidir que atitudes tomarem. Essas atitudes deverão estar contidas em mensagens enviadas à vila, cuja resposta será devolvida (supostamente) ao professor que irá transmiti-la aos moradores.

O Drama privilegia o contexto dramático - o 'onde' do Drama é comum ao grupo todo; os participantes conversam e discutem sobre ele e sobre a possibilidade de alterá-lo, se for o caso. O papel do professor se concentra em intensificar o contexto dramático, questionar as atitudes dos alunos, levantar implicações. São frequentes papéis coletivos para os alunos: moradores de uma ilha isolada, grupo de alunos em uma expedição na floresta, exploradores de terras desconhecidas. Nesse caso, os grupos formados a partir da identificação de interesses comuns, planejam ações coletivas. A força do coletivo intensifica a energia da experimentação e a dimensão emocional relacionada com o tema e as situações exploradas. Podemos dizer que o Drama contextualiza o 'onde', 'quem' e 'o quê' do Jogo Teatral.

John Shotter, em Living in a Wittgensteinian world: beyond theory to a poetics of practices (1996) refere-se a Poética do Espaço (1991), de Gaston Bachelard, chamando atenção ao drama como ética social: "Como podemos interpretar uma 
experiência intersubjetiva e incorporada onde já é entendido que os significados são inevitavelmente plurais, multivocais e contraditórios?" (Shotter, 1996, p. 296).

Doreen Massey ao analisar a significação poética do espaço, lembra que "todo espaço, e o espaço global em particular, sendo sobre relações, fraturas, descontinuidades, práticas de engajamento [...] sistemas de autoridade, poderiam ser considerados como 'cartografias do poder'" (2005, p. 20). As práticas do Drama, em particular, dependem da habilidade para re-imaginar o espaço, reformatar as identidades no espaço, criar um espaço adequado ao seu papel ficcional, compreender e explorar as relações de poder estabelecidas no espaço de jogo.

No caso de uma possível associação entre Drama e Jogo Teatral, o professor conduz o processo indicando aos participantes que, através do jogo, manifestem-se exclusivamente pela expressão física e, gradualmente, pela troca de olhares e indicação gestual, construam, no espaço de jogo, 'quem' são e 'o quê' estão fazendo, estabelecendo relações entre si, na construção de uma determinada experimentação dramática.

Em Drama Worlds, Cecily O'Neill (1995) apresenta um sumário de algumas qualidades estruturais à criação de tensões dramáticas, as quais considera particularmente úteis lembrar ao estruturar um processo de Drama. Conclui, dizendo:

Estes aspectos e recursos dramáticos são usados por dramaturgos, reiteradamente, quando planejam ocasiões e situações nas quais seus personagens podem encontrar-se e interagir. Personagens, em Drama, fazem pronunciamentos, trazem noticias, narram eventos, questionam, persuadem, suplicam, acusam, julgam e brigam uns com os outros. Eles pregam peças, contam piadas, se envolvem em disputas fisicas e verbais, dançam, cantam, rezam, rogam pragas, ameaçam, elogiam, culpam, fazem profecias, lamentam em luto, todas essas e outras coisas em uma grande variedade de formas. No processo do Drama, todas essas possibilidades estão disponíveis aos participantes e podem ser selecionadas como ações-chave em episódios específicos da estrutura dramática (O’Neill, 1995, p. 135).

As questões e os exemplos apresentados acima indicam e relacionam diferentes abordagens possíveis na prática do Drama. Se usarmos a 'mobilidade' como metáfora contemporânea para deslocamentos ou tradução, é possível observar que as propostas metodológicas para o ensino e criação em Teatro se transformaram a partir de investigações conceituais e práticas.

As interações entre Drama e Jogo Teatral representam a associação ideal entre contextos real e ficcional e propõem participações diferenciadas dos alunos. O jogo abre espaço para o 'colocar-se'. O Drama agrega as diferenças oferecendo suporte às opiniões antagônicas com base nas suas representações de sujeitos sociais distintos, questão essencial ao teatro.

Experiência realizada nesse sentido, a partir da identificação de cinco locais distintos de um bairro de Florianópolis, levantamento de suas histórias passadas e seleção de uma delas para cada local, integrando pessoas da comunidade ao grupo de atores, permitiu a vivência e a observação da interação entre Drama e Jogo em duas ocasiões distintas: no Bairro de Santo Antônio de Lisboa, em Florianópolis e no centro da cidade de Nova Trento. Ambas as experiências estão documentadas e publicadas pela Editora Hucitec em Teatro em Trânsito - a pedagogia das interações no 
espaço da cidade (2012), nessas experiências são focalizas a participação do público e sua interação com os atores.

\section{O professor dramaturg e o Drama na pós-modernidade}

As propostas de ensino do Drama na atualidade acentuam a atividade de construção da narrativa teatral em grupos, na qual o diretor, professor ou coordenador assume o papel de dramaturg ${ }^{3}$, intervindo diretamente na cena à medida que propõe ações, dirige o foco para determinadas opções dos atores, identifica e seleciona aspectos do texto teatral em construção, introduz materiais e propõe problemas, sendo um cocriador da narrativa dramática.

A intervenção indireta do professor se concentra na articulação entre os contextos social, ficcional e a ambientação cênica, selecionando aspectos da ficção que tenham ressonância no contexto real dos participantes e promovendo maiores ênfases nos aspectos sensórias e no engajamento emocional, por meio de diferentes estratégias a serem experimentadas no processo. $O$ texto teatral resultante, quer decorrente de abordagens centradas no resgate de histórias de vida ou da comunidade, quer na encenação de um texto dramático ou na colagem de fragmentos de textos diversos, dependerá da forma de articulação de seu pré-texto com as experimentações realizadas.

Como apontado no início deste texto, Cecily O'Neill introduziu a expressão 'pré-texto' em Drama para diferenciar o estímulo capaz de promover um crescimento orgânico daquele mecânico, em que o foco da ação nem sempre é coerente com a narrativa em processo. Para O'Neill, “[...] o pré-texto opera em diferentes momentos como uma espécie de 'forma-suporte' para os demais significados a serem explorados" (1995, p. 22). Como tal, responde tanto à necessidade de desconstruir o texto dramático a fim de adaptá-lo às condições e motivações locais, quanto à necessidade de parâmetros artísticos de estrutura e linguagem para transgredir os limites do cotidiano e do 'já visto'. Trata-se de um procedimento metodológico que permite delimitar as interações dos participantes a partir do cruzamento de fragmentos de um texto, da narração de trechos pelo condutor do processo, da inclusão de histórias de vida através do jogo teatral, possibilitando a identificação do grupo com as situações indicadas e sua ressonância no contexto real dos participantes.

Nesse sentido, os desdobramentos atuais do Drama refletem diferentes procedimentos experimentados no teatro contemporâneo; nele é comum observar o uso de peças clássicas como pré-textos, como componentes vitais de eventos teatrais. Os textos não são preservados como um significado específico a ser desvendado, interpretado e transmitido. Em vez disso, na perspectiva da pós-modernidade, essas peças são material esperando significação - são interpretados e explorados como objetos em um jogo. De acordo com Pavis (1992, p. 49), "O teatro pós-moderno recupera, ao retrabalhar, o patrimônio clássico, e necessita de normas clássicas para

${ }^{3}$ Profissional responsável por confeccionar, organizar e estruturar o roteiro ou texto a partir do trabalho de criação desenvolvido pelos atores, além de amparar os estudos teóricos necessários à montagem. Pode se confundir com a figura do encenador, como no caso de Bertolt Brecht (1898-1956), encenador e dramaturgo alemão, ou pode ser uma figura distinta daquela. 
estabelecer sua própria identidade".

A fonte clássica, ou pré-texto, opera como um enquadramento preliminar essencial - a extensão e o caráter do material adotado do trabalho original (um texto dramático, por exemplo) pode ser substancialmente alterado pela lógica interna do processo de ensaios. Para Grotowski (1969) o valor particular dos clássicos em seus encontros teatrais experimentais está no fato de que eles já existem como arquétipos na mente do público e carregam uma ressonância generalizada que está muito próxima do mito. Nas palavras do autor,

Todos os grandes textos representam um tipo de profundo abismo para nós [...] A força das grandes obras realmente consiste em seu efeito catalisador: elas abrem portas para nós, põe em movimento o maquinário de nossa autoconsciência [...] Para ambos, produtor e ator, o texto do autor é um tipo de bisturi possibilitando-nos abrir a nós mesmos, transcender a nós mesmos, achar o que está escondido dentro de nós (Grotowski, 1969, p. 49).

O sumário de aspectos estruturais de um processo de Drama pautado em Macbeth, de Shakespeare, apresentado por O'Neill (1995) subsidiou dois processos de Drama distintos desenvolvidos com estudantes do Curso de Licenciatura em Teatro da UDESC no ano de 2009.

O primeiro teve como foco questões de intrigas palacianas, ambição e jogos de poder. Os participantes trabalharam com fragmentos do texto e jogos de status, investigando a origem, as implicações e as consequências de um encadeamento de situações a partir do texto de Macbeth. A segunda experiência se concentrou na profecia e no universo da magia, examinando seu papel na deflagração das ações necessárias para a realização das previsões. O desenvolvimento desse processo esteve mais distanciado do texto e incorporou diferentes formas de rituais e histórias de vida.

A ênfase no sensorial e no engajamento emocional levou à busca de estratégias que dessem visualidade e permitissem o envolvimento pessoal e físico com a intertextualidade da narrativa em processo. A apropriação e reconstrução da narrativa, pelos participantes, implicou sua atualização para questões que thes fossem significativas, a incorporação da dimensão pessoal, a possibilidade de refletirem sobre seus significados ocultos, padrões de comportamento e aspectos da identidade.

Para que a criação de uma narrativa dramática seja bem sucedida, é necessário que os participantes vejam relevância no material sendo explorado. Nesse, é a 'tensão' que gera a energia do processo de investigação através da improvisação. $O$ estímulo inicial usado para introduzir o grupo no contexto da ficção é logo superado pelas ideias que esse gerou nos participantes. A partir daí, uma das propostas geradas é desenvolvida sob a forma de uma história e as demais são descartadas. Entre os problemas, usualmente apontados pelo professor, estão a dificuldade de fazer aflorar a complexidade das relações e situações presentes na narrativa e a impossibilidade de democratizar o processo com a inclusão das contribuições de todos os participantes.

Como apresentado no início do texto, algumas estratégias oferecem um suporte metodológico para que o professor consiga alcançar o engajamento, o envolvimento, a relevância e criação de tensão, apontados anteriormente. A estratégia e a teoria do 'estímulo composto', por exemplo, propõem um conjunto de estímulos - 
objetos, escritos, imagens, fotos - os quais sugerem propriedade e uso por parte de um ou mais personagens contidos no pré-texto, ou personagens que serão criados pelos participantes a partir da análise do material. A significação do conjunto de estímulos decorre da associação possível de ser estabelecida entre eles: a história de sua origem, a interação entre os documentos e fragmentos de texto (por exemplo: uma receita médica, uma página de diário, a anotação de um endereço, um boletim escolar, um bilhete, etc.). Documentos e objetos estão embutidos em uma história que requer a imaginação do grupo para ser completada - se o processo é bem encaminhado, as etapas dessa história não poderão ser preenchidas através de discussões; é necessário revelar seus problemas e implicações através da ação dramática, do jogo.

A eficácia do estímulo composto relaciona-se com os sentimentos despertados pela sua aparente autenticidade. Assim, a qualidade dos objetos e documentos gera a qualidade do envolvimento - daí a importância de detalhes tais como: fotocópias coloridas, diagramação e formatação dos textos, diferentes caligrafias para os manuscritos, envelhecimento de documentos quando for o caso, entre outras possibilidades. É necessário que os participantes criem empatia e identidade com as questões introduzidas e, para isso, o container deve ser coerente com seu conteúdo e introduzido com uma história que narre convincentemente o local em que foi encontrado.

Nos processos de Drama desenvolvidos na disciplina de Metodologia do Ensino do Teatro, na UDESC, o uso do estímulo composto permitia a imersão dos estudantes na proposta dramática e um maior engajamento, físico e emocional, com a narrativa. O pré-texto servia de suporte para a experimentação, mas os desdobramentos se davam de acordo com a capacidade dos participantes de jogar com os materiais postos à sua disposição.

Nas discussões mantidas com os participantes dos processos sobre a relação entre ensino do teatro e teatro contemporâneo buscávamos enfatizar as dimensões estética e artística da Pedagogia do Teatro. Ao focalizar especificamente o ensino do teatro no contexto da escola pública fundamental eram examinados os conceitos e proposições de democratização do acesso e do conhecimento, aquisição de linguagem e ampliação do capital cultural, formação do espectador e incentivo à leitura dos clássicos.

Segundo Bourdieu (1999, p. 56), "cada indivíduo herda de seu meio uma certa atitude em relação às palavras e ao seu uso que o prepara mais ou menos para os jogos escolares e consequentemente para a vida social". O acesso a textos que fazem parte do patrimônio cultural da humanidade não se restringe à prontidão para a leitura e encenações; sua abrangência sob a forma de citações e outras referências se estende às diferentes linguagens, experiências e códigos culturais - dos jogos de computador às formas de discurso usadas para construir narrativas e histórias pessoais. Esses e outros materiais podem ser postos à experimentação dos participantes em um processo de Drama que se aproxima das proposições contemporâneas de criação espetacular e investigação artística.

\section{Entre Drama e Performance}

Se o Drama, como um campo privilegiado para vivências estéticas delimitadas 
por contextos e circunstâncias ficcionais, induz tanto à identificação de papéis quanto a momentos de tensão, a Performance se apresenta como uma experiência de tradução de questionamentos/desejos/vivências do performer anteriores à sua apresentação. Essa tradução, por sua vez, permanece aberta aos insights e/ou provocações de cada apresentação.

Estar aberto a provocações faz parte de ambos os fazeres artísticos - se no Drama as provocações são introduzidas pelo professor, na Performance são a resposta dos atores/performers ao contato com o público. Drama e Performance, centrados no 'aqui e agora' da experiência, apresentam movimentos, deslocamentos, ou reposicionamentos contínuos; ambos buscando aquilo que foi melhor percebido e, como tal, concebido na vivência anterior.

Dessa forma, podemos aqui dizer sobre Drama e Performance que ambos se inserem nas experiências pós-modernas, compartilhando o que Féral (2008) considera como uma recusa a ser estabelecido ou fixado, vacilando entre deslocamento e reintegração. Nessa vacilação e recusa em ser fixado, afirma Féral, nós podemos novamente ver operando o "jogo da diferença" de Derrida (Féral, 2008).

'O que acontece' no Drama e na Performance não tem a ver com incorporação ou codificação de significados específicos e fechados - os participantes articulam ideias artísticas, éticas e políticas, através da vivência estética, para dar forma a memoriais, testemunhos, manifestos políticos e protestos. Essa característica curta e afiada do texto de ambas as manifestações artísticas permite que os sentidos sejam ativados e que apontem para o que está por trás de seus textos.

Derrida (2001, p. 181) afirma que "o que deve ser traduzido daquilo que é traduzível, pode somente ser o intraduzível". Os atos de tradução, segundo o autor, levam as ideias teóricas à ação através de eventos performáticos. Segundo Helen Nicholson (2005), esses eventos podem ser enquadrados para reflexão pedagógica e política.

Nesse sentido, o psicólogo social John Shotter (1996) enfatiza a importância dos momentos de conexão nas interações sociais, particularmente quando essas levam a novos insights e entendimentos compartilhados, que associam a prática da vida cotidiana com a arte da imaginação social. Assim, o Drama, como poética social, levanta questões que conduzem à interpretação da experiência intersubjetiva.

O campo do Drama dá visibilidade às variáveis da imaginação social - por um lado, é possível destacar a mobilidade e a dinâmica da intervenção social, por outro lado, as crenças tradicionais são desestabilizadas e os valores reconfigurados. Essas duas presenças constantes em processos de Drama apontam para a possibilidade de mudanças pessoais a partir da performance dos participantes como um processo de construção de novas identidades ao incorporar vivências de 'tornar-se' um outro alguém.

As performances individuais e coletivas são acentuadas em um processo de Drama, o que leva o participante a se perceber como criador da narrativa, fazendo com que o jogo artístico se dê por meio de sua presença efetiva/afetiva na proposta. Nesse espaço, subjetividades, dramaturgias e culturas diferentes interagem no campo do ensino e do espetáculo. O conceito de 'presença', portanto, é central no espaço do Drama na escola, uma vez que o enquadramento inicial convida os participantes a 'serem um outro alguém'. 
Derrida (2001) para pensar o cruzamento das significações a partir do jogo das diferenças, propõe o termo 'rastro' para aquilo que não podemos e/ou não queremos explicitar ou controlar. Nesse sentido, ao pensarmos em uma turma com 30 ou mais crianças, adolescentes ou adultos, focalizar os rastros de suas presenças, tanto na ordem de seus discursos falados, escritos, posturais, opções por signos, locais de ação, objetos de cena ou figurino, remete a outros elementos que se associam, ou não, colocando o diretor/professor no rastro das diferenças - ponto de partida para o jogo como elemento essencial ao Drama. Cruzamentos e jogo são a base e a estrutura do Drama, que busca identificar as diferenças como aquilo que lhe é essencial e o faz acontecer.

Como rastreador de diferenças, o professor, ao trabalhar com o Drama, as situa no patamar da criatividade, da essencialidade do processo, sem as quais esse não acontece. Essas diferenças são expostas pelos participantes ao transporem para sua performance no Drama, os interesses, desejos, posicionamentos, crenças que possuem.

Como apontamos em nossos principais estudos realizados sobre este método Cabral (2006) e Pereira (2015) - a convenção 'processo' é entendida como primordial para a instauração da vivência dramática.

[...] o Drama se caracteriza por ser um fazer teatral em processo e a criação se dá no ato próprio de experimentar e desenrolar as situações propostas. Ele não tem como objetivo a criação de um produto, a apresentação, a repetição (em formato de ensaio, por exemplo) que leva, muitas vezes, a um esvaziamento da experiência por conta da imposição de marcas e formas (Pereira, 2015, p. 129).

A prática do Drama com formação de grupos e identificação de campos de interesse, inclui, em suas abordagens metodológicas, tipos de confrontos que permitam explicitar diferentes perspectivas. A atuação do professor, no sentido de apontar para e questionar as diferenças, estimula os alunos a identificá-las sob seus pontos de vista, levando-o a esclarecer as implicações e possíveis aproximações com ações em campos sociais mais amplos.

Ao professor cabe, assim, identificar as raízes dos campos de interesse dos alunos e criar roteiros que incluam a possibilidade de questionar crenças e valores. $O$ trabalho em grupos e a identificação de raízes e campos de interesse distintos são duplamente oportunos para serem compartilhados - ao identificar e compartilhar pontos de vista os participantes percebem que suas posturas e ideias não estão completas, acabadas ou delimitadas, mas estão sempre incorporando algo, tornando-se diferenciadas.

Um processo de Drama, em cada instauração, ainda que a partir de um mesmo tema ou pré-texto, nunca estará completo ou delimitado, mas sempre em movimento, aberto aos conteúdos que surgirão ao se colocar em jogo e, nesse sentido, os processos decorrem da identidade cultural dos participantes e se articulam com ela.

Para visualizar alternativas próprias de autoria dos alunos participantes, o professor precisa ter em mente que o aluno aprende ao fazer, falando sobre o que está fazendo, em grupo. O Drama oferece um contexto coletivo aberto a alternativas de autoria dos participantes e o professor, tal como um maestro, torna-se o articula- 
dor das diferentes propostas, organizando o espaço e o tempo para que cada grupo apresente sua proposta.

Por meio do fazer teatral a ação do professor se vincula à estética, à ética e à política e se torna uma forma de combater padrões de comportamento que reproduzem o senso comum e bloqueiam a percepção crítica ao nível cultural. Esse entendimento refuta o ensino-instrução, o qual supõe que todos construam conhecimento da mesma forma e possam ser avaliados da mesma maneira; exige o questionamento do que se ensina e da maneira pela qual se ensina. Se o fazer artístico na experimentação do Drama for significativo e tiver ressonância com os interesses e preocupações dos participantes, causará impacto e provavelmente mudanças de percepção.

Após a vivência de um processo ou em um episódio específico desse, pode haver um compartilhamento público a depender da inclinação do grupo. Essa apresentação pode ser apenas para a própria classe - de experimentos realizados em pequenos grupos - ou para a escola, podendo incluir convidados dos participantes.

Quando há um compartilhamento com uma plateia exterior, abre-se espaço para que outros jogos sejam estabelecidos com o público e a performance artística proporá que esse outro grupo seja questionado sobre as ações e questões exploradas no processo.

Para não ser entendida como uma apresentação formatada, em estudo realizado sobre Drama foi proposta a ideia de 'vivência dramática com plateia' - "[...] o condutor propunha um roteiro aberto, criado a partir da rememoração dos acontecimentos ocorridos no processo e, diante de um outro grupo, conduzia as crianças a experimentarem novamente algumas situações" (Pereira, 2015, p. 288). Pode-se, também, planejar que algum episódio seja experimentado na presença de um outro grupo ou em conjunto com esse. Há, nessa sugestão, também uma relação com a Performance, por entendermos que novas criações podem ocorrer durante essa vivência compartilhada, pois se propõe que os participantes joguem, libertando-as da exigência de reproduzirem ações de forma mecanizada.

Como exposto ao longo do texto, o Drama se associa aos princípios que regem a ação pedagógica e não à implementação de uma determinada metodologia - rejeita a receita do 'como fazer'. Os princípios comuns ao Drama, à cultura e à pedagogia, incluem 'a voz de cada participante' deflagrando originalidade, subjetividade e a necessidade de 'colocar-se' no 'aqui e agora' do evento, como ocorre com o performer.

\section{Drama e Linguagem}

Cecily O'Neill, Jonothan Neelands e John O'Toole expandiram na teoria e na prática aspectos distintos do Drama, que marcam hoje suas especificidades na forma de conduzir os processos e estabelecer subáreas metodológicas. Embora O'Neill e O'Toole se incluam na subárea do Drama e Neelands se identifique com o caminho do Teatro, não consigamos perceber uma diferença que justifique essa separação, nem em seus textos, nem em suas práticas, uma vez que, ainda que por diferentes vias, todos instauram um espaço de jogo que oferece concretude e permite a imersão dos participantes na proposta. A dramaticidade de um pré-texto conduzido por O'Neill é inigualável, assim como os papéis representados por O'Toole no decorrer 
de suas oficinas.

É comum, e ainda frequente, encontrar professores e pesquisadores que participaram de experiências dramáticas com Dorothy Heathcote que afirmam que ela, assim como Gavin Bolton, reunia as habilidades descritas na identificação das três vertentes apresentadas no início deste texto. A importância de estabelecer as identificações e diferenças está no potencial teórico que elas representam para o cruzamento com outras áreas de conhecimento e para a reflexão sobre a interação entre arte, pedagogia e política na prática do Drama.

Pesquisas e experimentos cênicos realizados desde 1995, quer com estudantes de graduação, professores voluntários, crianças ou adolescentes em escolas ou comunidades, revelam a identificação e aproximação natural dos coordenadores ou mediadores com uma das tendências destacadas neste texto.

Em diferentes propostas, realizamos investigações que propunham diálogos com diversas abordagens metodológicas, dos Jogos Teatrais de Spolin a fragmentos de textos, de histórias pessoais a manifestos artísticos, de pré-textos clássicos a histórias desconhecidas. O essencial é entender que os participantes serão os criadores da narrativa impulsionada pelas escolhas de estratégias realizadas pelos professores/ condutores. Essa criação se dará por meio do espaço de jogo aberto quando da instauração de um processo de Drama.

A identificação, seleção e exploração das convenções dramáticas que introduzem ações para criação de contexto, construção da narrativa, da linguagem poética e da reflexão crítica, constituem-se como os fundamentos para o desenvolvimento da linguagem e do conhecimento do fazer teatral. Em termos pedagógicos, oferece ao aluno os meios e os instrumentos para se autonomizar no processo de criação.

O professor como ator ou personagem cria impacto, aponta implicações, derruba preconceitos com o uso da ironia, dá pistas sobre o currículo ou a agenda oculta. Ele coloca sua performance como elemento de jogo com os participantes, expondo-se como artista-criador, cocriador do processo, que se dá 'em ato'.

O prazer da investigação e criação cênica, em certos contextos e circunstâncias, dependerá, em parte, das intenções artístico-pedagógicas dos professores. Buscamos apontar, ao longo do texto, diferentes opções de diálogo que o condutor de um processo de Drama pode fazer de acordo com suas habilidades ou necessidades específicas. Essas associações indicam diferentes ênfases do professor em abordagens de Drama que incluam ou alternem interpretação e performance, improvisações e apresentação em um espaço de jogo ampliado e alicerçado por um contexto ficcional.

\section{Referências}

Ackroyd, Judith. Research Methodologies for Drama Education. Stoke on Trent: Trentham Books Ltd, 2006.

Bachelard, Gaston. The Poetics of Space. Boston: Beacon Press, 1991.

Bourdieu, Pierre. A Dominação Masculina. Rio de Janeiro: Bertrand Brasil, 1999. 
Cabral, Beatriz. Teatro em Trânsito - a pedagogia das interações no espaço da cidade. São Paulo: Hucitec, 2012.

Drama como método de ensino. São Paulo: Hucitec, 2006.

Derrida, Jacques. What Is a "Relevant" Translation? In: Critical Inquiry. Chicago: The University of Chicago Press, vol. 27, 2001.

Féral, Josette. Por uma poética da performatividade: o teatro performativo. In: Revista Sala Preta. São Paulo: ECA/USP, n. 8, 2008.

Grotowski, Jerzy. Towards a Poor Theatre. London: Methuen, 1969.

Massey, Doreen. For Space. London: Sage, 2005.

Neelands, Jonothan. In Memory of Dorothy Heathcote. In: Research in Drama Education - the journal of applied theatre and performance. London: Routledge, vol. 17, 2012.

Structuring Drama Work. London: Cambridge University Press, 1990.

Nicholson, Helen. Applied Drama: the gift of theatre. London: Palgrave, MacMillan, 2005.

O'Neill, Cecily. Drama Worlds: a framework for process drama. Portsmouth: Heinemann, 1995.

O'Toole, John. The Process of Drama. London: Routledge, 1992.

Theatre in Education: new objectives for theatre, new techniques in education. London: Hodder and Stoughton, 1976.

Pavis, Patrice. The Intercultural Performance Reader. London: Routledge, 1996.

Pereira, Diego de Medeiros. Drama na Educação Infantil: experimentos teatrais com crianças de 02 a 06 anos. 2015. 293 f. Tese (Doutorado em Teatro) - Programa de Pós Graduação em Teatro, Universidade do Estado de Santa Catarina, Florianópolis, 2015.

Shotter, John. Living in a Wittgensteinian World: beyond theory to a poetics of practices. In: Journal for the Theory of Social Behaviour, vol. 26, 1996.

Spolin, Viola. Improvisation for the Theater. Evanston: Northwestern University Press, 1963.

Recebido em: 04/06/2017

Aprovado em: 04/06/2017 